\title{
Residues from single-stage dry de-dusting and desulphurization of sinter plant off-gas: enabling partial recirculation by air classification
}

\author{
C. Lanzerstorfer $\cdot$ R. Neuhold
}

Received: 20 March 2014/Revised: 8 October 2014/Accepted: 27 October 2014/Published online: 5 November 2014

(C) Islamic Azad University (IAU) 2014

\begin{abstract}
In iron ore sinter plants, the process off-gas is de-dusted by electrostatic precipitators which are installed upstream of the fan. For further reduction of emissions, a second cleaning stage can be installed. This stage usually comprises a sorption process for removal of acid gases and polychlorinated dibenzo(p)dioxins and furans, followed by a fabric filter. The residue from the first de-dusting stage can be recirculated to the sintering process. The residue from the second cleaning stage has to be disposed of in landfill sites. A new single-stage off-gas cleaning concept for sinter plants comprises an entrained flow sorption process and a fabric filter, installed upstream of the fan. In this way, the investment costs for the off-gas cleaning system can be reduced significantly. However, it would become necessary to dispose of most of the residue. In this work, air classification of a residue equivalent to that of a single-stage off-gas cleaning unit was investigated with the aim of producing a fraction of this residue with reduced sulphur and chloride concentrations which can then be recycled. The results confirm that air classification is a suitable process. In order to maintain raw mixture targets for chlorine or to avoid chlorine enrichment in the raw feed, the recommended dust recycling rate is $66 \%$ with air classification which is an improvement over the allowed rates without air classification of $42 \%$.
\end{abstract}

C. Lanzerstorfer $(\bowtie)$

School of Engineering/Environmental Sciences, University of Applied Sciences Upper Austria, Stelzhamerstraße 23, 4600 Wels, Austria

e-mail: christof.lanzerstorfer@fh-wels.at

R. Neuhold

Siemens VAI Metals Technologies GmbH, Turmstraße 44, 4031 Linz, Austria
Keywords Sinter plant - Gas cleaning residue . Recycling · Air classification

\section{Introduction}

In the integrated iron and steel making process, the agglomeration of iron ores and fine-grained recycled ironcontaining materials like dusts, sludge and scale in the sinter plant is an essential process step. Due to the high volume of off-gas, sinter plants are responsible for a lot of the atmospheric emissions from an integrated steelworks (EC 2012, p. 92). The off-gas from a sinter plant is usually de-dusted by electrostatic precipitators (EPs) or cyclones which are installed upstream of the induced draft fan (Eisen et al. 1996). In some sinter plants, advanced EPs are installed (Kim et al. 1997; Buchwalder et al. 2008; Bastürk et al. 2009) to achieve lower dust emissions. To comply with lower emission limits for dust, $\mathrm{SO}_{2}$ and polychlorinated dibenzo(p)dioxins and furans ( $\mathrm{PCDD} / \mathrm{F})$, additional emission reduction measures have been taken at several sinter plants. At some of these sinter plants, adsorbent is injected prior to the EP to reduce PCDD/F emissions by an entrained flow adsorption process. However, a PCDD/F concentration below $0.1 \mathrm{ng} / \mathrm{m}^{3}$ (S.T.P) cannot be achieved because of the limited injection rate of the carbon-containing adsorbent due to the risk of an explosive mixture in the EP (Bonte et al. 2003; Bastürk et al. 2009). Therefore, in the last two decades, a second-stage off-gas cleaning system was installed at several sinter plants. This additional cleaning stage can be a wet system or a dry system (Menad et al. 2006; Delwig et al. 2007; Guerriero et al. 2009). However, dry systems using a sorption process for the separation of acid gases, and a fabric filter for final dedusting, are predominantly used (Weiss 1998; Leroy et al. 
Fig. 1 Typical flow diagram for two-stage off-gas cleaning of a sinter plant (upper part) and for the new single-stage design (lower part)
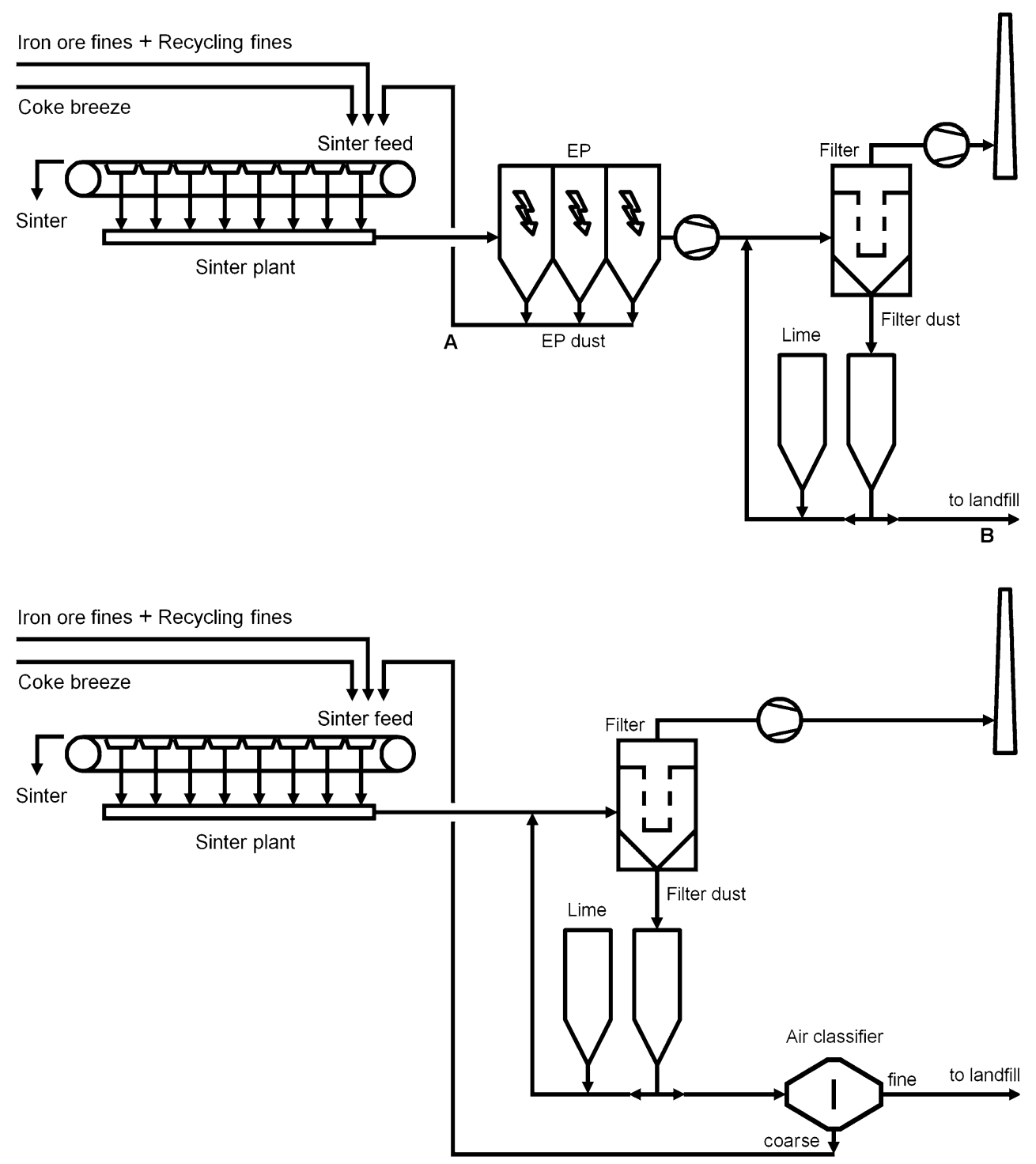

2007; Lanzerstorfer et al. 2008; Yu et al. 2009). By mixing a carbon-containing sorbent to the sorbent for acid gas separation, PCDD/F emissions can also be reduced by this process (Schuster et al. 2005; Fleischanderl et al. 2006). A typical flow diagram is shown in the upper part of the Fig. 1.

The solid residue from de-dusting with EPs or cyclones is usually recycled to the feed material of the sinter plant. In some sinter plants, the dust collected in the last electrical field of the EP is excluded from recycling because of the high concentration of chloride (EC 2012, p. 114).

The residue from dry second-stage off-gas cleaning has to be disposed of in landfills because of the high concentrations of sulphate and chloride which are the result of the separation of sulphur dioxide and hydrogen chloride and the collection of the finest dust fraction (EC 2012, p. 128). In order to avoid landfill disposal, leaching of this residue with water was investigated, yielding a material that can be reutilized in the cement industry (Xu et al. 2012). However, a significant amount of salt water, which has to be discharged, is generated by this process. The solid residue from a wet second-stage off-gas cleaning unit is similar to the residue generated from water leaching. The recycling of the residue from a wet second-stage off-gas cleaning to the sinter plant feed has been demonstrated successfully on an industrial scale. Even for the PCDD/F, no negative upcycling effect was observed (Smit et al. 2000).

A new concept for cleaning the sinter plant off-gas consists of single-stage, dry de-dusting and desulphurization by an entrained flow adsorption process with a fabric filter for final de-dusting installed upstream of the fan (Kazyuta et al. 2004). The realization of this process is not economic because the resulting residue would be a mixture of the two residues which would contain all of the chloride 
and sulphate in the sinter dust, as well as the sulphate from off-gas desulphurization and the chloride from the separated hydrogen chloride. Therefore, recycling this residue to the sinter feed is impossible.

In this work, the application of air classification was investigated to produce a fraction of the residue from a single-stage, dry de-dusting and desulphurization off-gas cleaning system of a sinter plant which is characterized by reduced chlorine and sulphur concentrations that makes it suitable for recirculation in the sinter plant. A flow diagram for such a system is shown in the lower part of Fig. 1. As there is no such single-stage off-gas cleaning system in operation, for the investigation, the residues from the twostage, dry, off-gas cleaning system of an industrial iron ore sinter plant were mixed in the appropriate ratio. The results of this study are intended as a basis for future economic evaluation of the new single-stage off-gas cleaning concept. The work was carried out in summer 2012 at the University of Applied Sciences Upper Austria.

\section{Materials and methods}

\section{Residues}

The residues originate from an industrial iron ore sinter plant with a two-stage, dry, off-gas cleaning system. The first cleaning stage is a four field EP installed upstream of the fan, and the second stage comprises a sorption process using hydrated lime as a sorbent and a fabric filter for final de-dusting. The residue samples were collected from the dust discharge system of the EP (sampling point $\mathrm{A}$ in the upper part of Fig. 1) and the fabric filter (sampling point B in the upper part of Fig. 1).

Sample preparation and dry classification

The residue for the classification tests was produced by mixing both residues in a laboratory plough-share drum mixer in a mass ratio of 1.0-2.3 (fabric filter dust to EP dust).

For air classification, a laboratory air classifier 100 MZR from Hosokawa Alpine was used. After entering the classifier, the air flows through the classifying wheel in centripetal direction. The classifying wheel extracts the fines from the feed material and conveys them to the fines discharge. The material rejected by the classifying wheel is collected in the coarse sample container.

In the first classification step, the finest dust fraction was separated from the mixture and collected as Particle Class 1 in the cyclone at the outlet of the classifier. The remaining coarse fraction was used as feed material in the next classification step, where the classifier was operated at reduced speed so the cut-size diameter of the classification became a coarser particle size. In this second classification step, the material was split into Particle Class 2 and a new coarse fraction. This procedure was repeated twice more, so that the dust mixture was separated into five dust fractions. In the first classification step, some fine dust material is lost when passing through the cyclone at the outlet because the collection efficiency of the cyclone for very fine material is limited. The amount of fine dust lost was calculated by a mass balance for this classification.

\section{Characterization of the residues}

The volumes of the dust samples were reduced to the volume suitable for the various measurements using sample dividers (Retsch PT100 and Quantachrome Micro Riffler) which were applied repeatedly.

The particle size distribution was measured using a laser diffraction instrument with dry sample dispersion from Sympatec, type HELOS/RODOS.

For determination of the concentration of the watersoluble $\mathrm{Cl}$ in the samples, approximately $2 \mathrm{~g}$ of a sample were leached in $200 \mathrm{ml}$ of deionized water for $1 \mathrm{~h}$. To aid the leaching process, the samples were placed in an ultrasonic bath. After leaching, the remaining solids were separated by filtration. The filter cake was flushed with $50 \mathrm{ml}$ deionized water. The filters were dried at $105{ }^{\circ} \mathrm{C}$, and the leaching process was performed a second time to check for completeness of leaching. The amounts of $\mathrm{Cl}$ found in the second leachate were always $<2 \%$ of the amount in the first leachate. The chemical analyses were carried out by ion chromatography (Dionex ICS-1000).

The concentrations of the mineral components $\mathrm{Ca}, \mathrm{Mg}$, $\mathrm{Al}, \mathrm{Si}, \mathrm{Fe}$ and $\mathrm{S}$ were analysed by $\mathrm{X}$-ray fluorescence spectroscopy with a Thermo Fisher Advant X instrument. For the measurement, a tablet was pressed from the fine granular powder. Because of the high oxygen concentration in sinter plant off-gas, the results are presented in oxidized form as $\mathrm{CaO}, \mathrm{MgO}, \mathrm{Al}_{2} \mathrm{O}_{3}, \mathrm{SiO}_{2}, \mathrm{Fe}_{2} \mathrm{O}_{3}$ and $\mathrm{SO}_{3}$.

\section{Equilibrium calculations}

To estimate better the behavior of recycled residue from a single-stage, dry de-dusting and desulphurization system during the sintering process, the equilibrium composition was calculated in dependence of the temperature. For this calculation, the program HSC Chemistry ${ }^{\circledR} 5.1$ (Outotec Oy, Pori, Finland) was used. The typical composition for the sinter off-gas was chosen with the following mole fractions: $\mathrm{N}_{2}: 72 \% ; \mathrm{O}_{2}: 15 \% ; \mathrm{CO}_{2}: 5 \%, \mathrm{CO}: 1 \%$ and $\mathrm{H}_{2} \mathrm{O}$ : $7 \%$. The sinter feed material including the recycled residue was estimated based on the following simplifying assumptions: the sinter feed material without recycled 
residue consists of $85 \% \mathrm{Fe}_{2} \mathrm{O}_{3}, 10 \% \mathrm{CaO}$ and $5 \% \mathrm{SiO}_{2}$; the mass ratio of sinter feed and recycled EP dust results from a dust concentration in the sinter off-gas of $1.0 \mathrm{~g} / \mathrm{m}^{3}$ (STP); for the recycled residue, the mixing ratio of EP dust and fabric filter dust is the same as the ratio of their occurrence; in the residue chloride is present as potassium and sodium is chloride; the ratio of potassium chloride to sodium chloride in the sinter dust is 10:1 (Peng et al. 2009); all sulphate in the residue is present as calcium sulphate, and the surplus of calcium in the residue is present as calcium oxide.

\section{Characterization of the classification}

A classification is defined by its size selectivity or grade efficiency curve $\mathrm{T}(\mathrm{x})$, which is defined according to Eq. (1), where $\mathrm{c}$ is the fraction of coarse material, $q_{0}(\mathrm{x})$ is the frequency distribution of the feed and $q_{\mathrm{C}}(\mathrm{x})$ is the frequency distribution of the coarse material.

$T(x)=c \cdot \frac{q_{\mathrm{C}}(x)}{q_{0}(x)}$

The classification process can be characterized by the cut size $\mathrm{x}_{\mathrm{t}}$ and the cut sharpness $\kappa$. The cut size is the particle size corresponding to $T(x)=0.5$. The sharpness of classification is defined by Eq. (2),

$\kappa=\frac{x_{\mathrm{t}, 25}}{x_{\mathrm{t}, 75}}$

where $x_{\mathrm{t}, 25}$ is the particle size corresponding to $T(x)=0.25$ and $x_{\mathrm{t}, 75}$ is the particle corresponding to $T(x)=0.75$.

\section{Recycling calculation}

In order to recycle the combined residues to the sinter plant, a certain removal ratio for the unwanted components is required, depending on the input limits at the sinter plant for these components. Removal of such components by classification always means a recovery ratio of the material $R$ of $<1$. The higher the required removal ratio, the lower the permitted recovery ratio for the residue. The removal ratio for a certain component $R_{\mathrm{i}}$ is defined by Eq. (3),

$R_{i}=1-\frac{m_{i, c}}{m_{i, 0}}$

where $m_{\mathrm{i}, 0}$ is the mass of the component in the residue and $m_{\mathrm{i}, \mathrm{c}}$ is the mass of this component in the coarse fraction of the residue which is to be recycled. The recovery ratio is defined as the ratio of the mass of the coarse fraction of the residue which is to be recycled, $m_{\mathrm{c}}$, to the total mass of the residue, $m_{0}$. The recovery ratio as a function of the removal ratio was calculated for chloride and sulphur, as well as for the valuable components iron and calcium.

\section{Results and discussion}

Size distribution of the original residues and the fractions produced

The particle size distributions of both original residues are shown in the left of Fig. 2. The particle size of the residue from the fabric filter with a mass median diameter $d_{50}$ of $4.1 \mu \mathrm{m}$ is much smaller compared to the particle size of the residue from the EP with a $d_{50}$ of $51 \mu \mathrm{m}$. Therefore, it can be expected that air classification can be used to separate a mixed residue into two fractions which are more or less similar to the two original residues. However, it has to be considered that the size distribution of the fabric filter dust is very strongly influenced by the size distribution of the sorbent used.

The speed of the classifier in the four classification runs was $21,000,10,500,5,000$ and $3,000 \mathrm{rpm}$. The mass fractions for the five particle classes produced are summarized in Table 1, together with their mass median diameters. The particle size of the lost fraction cannot be precisely given. However, it is clear that it is smaller than for Particle Class 1. The particle size distributions of the five residue fractions produced, Particle Class 1 to Particle Class 5, are shown in the right of Fig. 2.

\section{Characterization of classification}

The calculated grade efficiency curves of the classification runs are shown in Fig. 3. In the four classification runs, the cut-size diameter was 5.6, 9.6, 19.5 and $41 \mu \mathrm{m}$. The quality of the separation was not especially high because some fine material was always found in the coarse fraction. The cut sharpness for the four classification runs is in the range of $0.51-0.55$, whereas for a sharp classification, the cut sharpness would be in the range of $0.6-0.8$.

Chemical composition of the original residues and the fractions produced

The concentrations of the unwanted components (chloride and sulphate) in the original residues and the residue fractions produced are shown in Fig. 4, together with the concentrations of the valuable components iron oxide and calcium oxide. The composition of the coarsest Particle Class 5 is very similar to the composition of the EP dust. This is not surprising as there is no such coarse material in the fabric filter dust. The lower concentration of chlorides in the coarsest fraction compared to the EP dust can be explained by the fact that the chlorides in the EP dust are enriched in the smaller particles (Gebert 1996). 

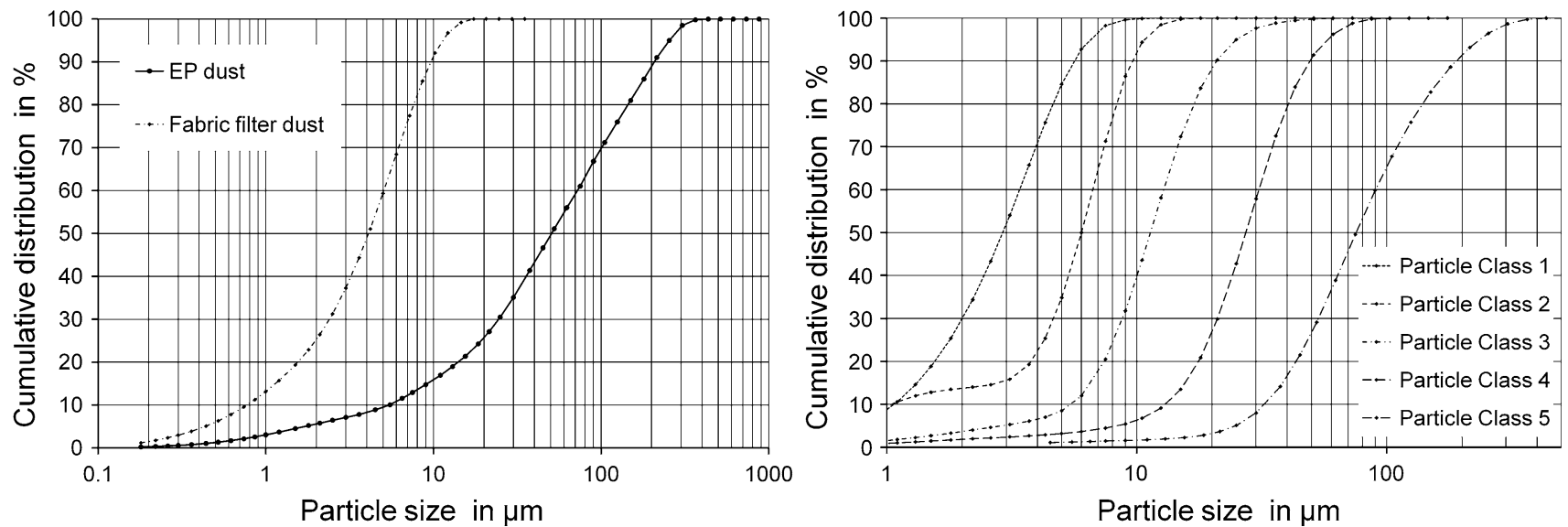

Fig. 2 Particle size distribution of fabric filter dust, EP dust (left) and particle classes produced (right)

Table 1 Data of the produced fractions

\begin{tabular}{lcc}
\hline Sample & Mass fraction in $\%$ & $d_{50}$ in $\mu \mathrm{m}$ \\
\hline Loss & 3.3 & - \\
Particle class 1 & 19.4 & 2.91 \\
Particle class 2 & 8.4 & 6.0 \\
Particle class 3 & 13.2 & 11.4 \\
Particle class 4 & 18.9 & 27.4 \\
Particle class 5 & 36.8 & 80.6 \\
\hline
\end{tabular}

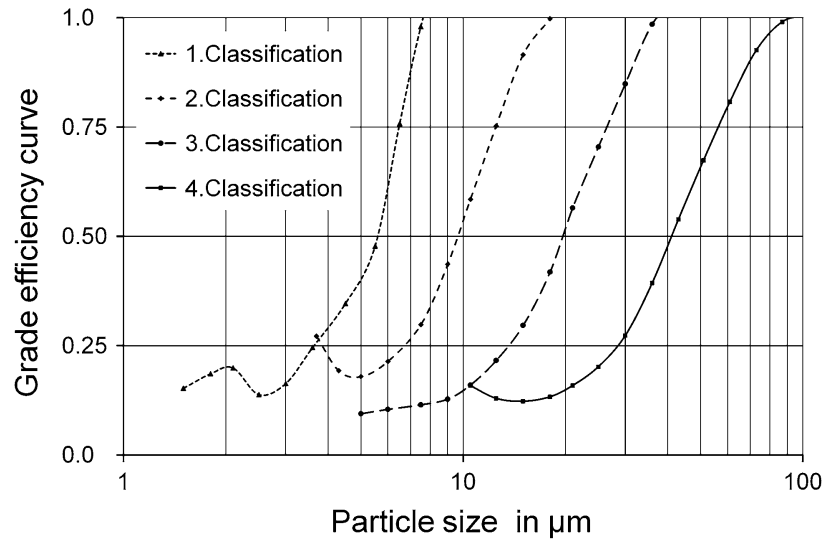

Fig. 3 Calculated grade efficiency curves

The composition of the finest material, Particle Class 1, is quite similar to the composition of the fabric filter dust. However, there is an increased amount of chloride and iron oxide in this material compared to the fabric filter dust. This can be explained by the mass fraction of about 0.1 of the EP dust that is smaller than $5 \mu \mathrm{m}$. From Particle Class 1 to Particle Class 5, the concentration of chloride, calcium and sulphate decreases, whereas the concentration of iron oxide increases.

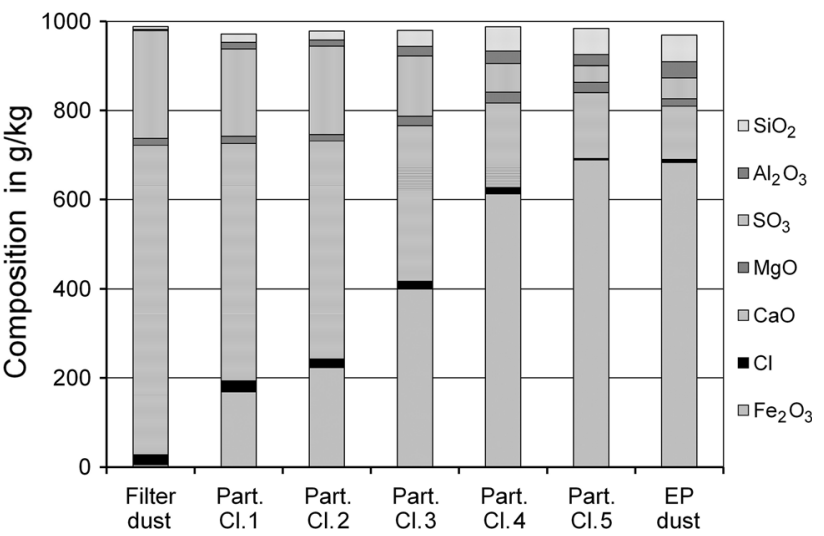

Fig. 4 Composition of the original residues and residue fractions produced

Chemical equilibrium calculations for recycling conditions

For the composition of the solid feed material in the equilibrium calculation, the results of the chemical analysis of the actual residues were used. The resulting composition in mole fractions was: $\mathrm{Fe}_{2} \mathrm{O}_{3}: 67.1 \%$; $\mathrm{CaO}: 22.5 \%$; $\mathrm{SiO}_{2}$ : $10.5 \%$; $\mathrm{CaSO}_{4}: 0.013 \%$; $\mathrm{KCl}: 0.0039 \%$ and $\mathrm{NaCl}$ : $0.0004 \%$. The results of the equilibrium calculation are shown in Fig. 5. The left of Fig. 5 shows the dependence of the distribution of chlorine on the temperature. It has to be mentioned that in the sintering process, the off-gas is not in equilibrium with the sinter material. This is evident from the $\mathrm{CO}$ concentrations: in the real off-gas, the $\mathrm{CO}$ content is about $1 \%$ (Reidetschläger et al. 2012), whereas the maximum $\mathrm{CO}$ concentration in the calculated equilibrium is only a few ppm. Nevertheless, this calculation can give an indication about the behavior of recycled chlorine and sulphur. At low temperatures, all chlorine is present in the 

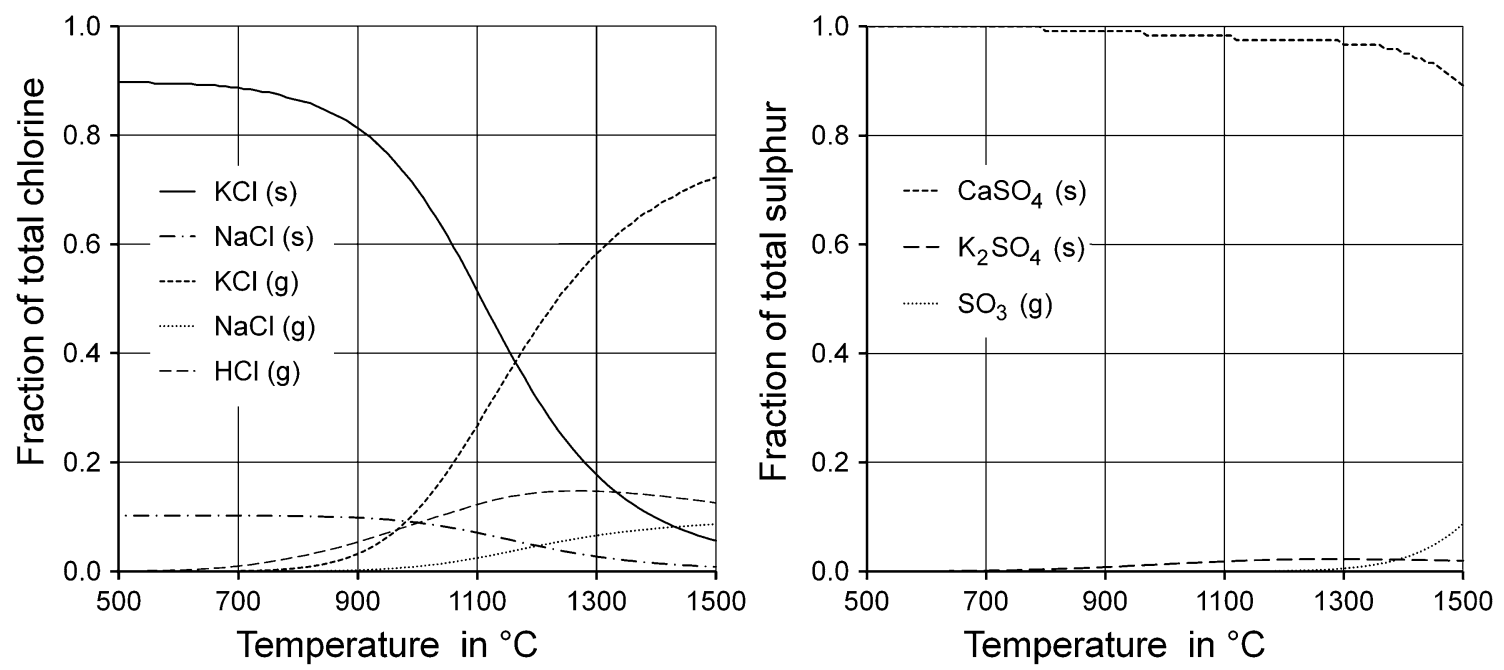

Fig. 5 Temperature dependence of the distribution of chlorine (left) and sulphur (right)

solid phase as alkali chlorides. At the maximum temperature during sintering of $1,300-1,480{ }^{\circ} \mathrm{C}$, the alkali chlorides constitute $75-90 \%$ in the gas phase, depending on the temperature. That means that most of the chlorine contained in the residue would be released to the off-gas during the sintering process when the mixed residue is recycled to the sinter feed. As a consequence of this, there would be a build-up of chlorine in the whole cycle consisting of the off-gas, the residue from off-gas cleaning and the sinter feed. Therefore, a discharge mass flow for chlorine is required, preferably in the form of a highly chlorine concentrated fraction of the residue.

The right of Fig. 5 shows the dependence of the distribution of sulphur on the temperature. At sinter temperature, the gypsum contained in the residue is stable to a great extent. Depending on the actual sinter temperature, only up to $10 \%$ of the sulphur is released to the off-gas during the sintering process when the mixed residue is recycled to the sinter feed. Therefore, a way of discharging sulphur is less important.

Permissible recycling rate for the residue

A requirement of recycling of the mixed residue from a single-stage, dry de-dusting and desulphurization system of a sinter plant would be to limit the mass rate of recycled chlorine and sulphur. The limits could be the actual mass flow of chloride and sulphur with the recycled EP dust. In the sinter plant from which the residue samples were taken, the EP dust represents about $70 \%$ of the residue produced. This dust is recycled, whereas the fabric filter dust is discharged. With a single-stage off-gas cleaning system, the recycling of $42 \%$ of the combined residue would result in an equal mass flow of chlorine back to the sinter plant.

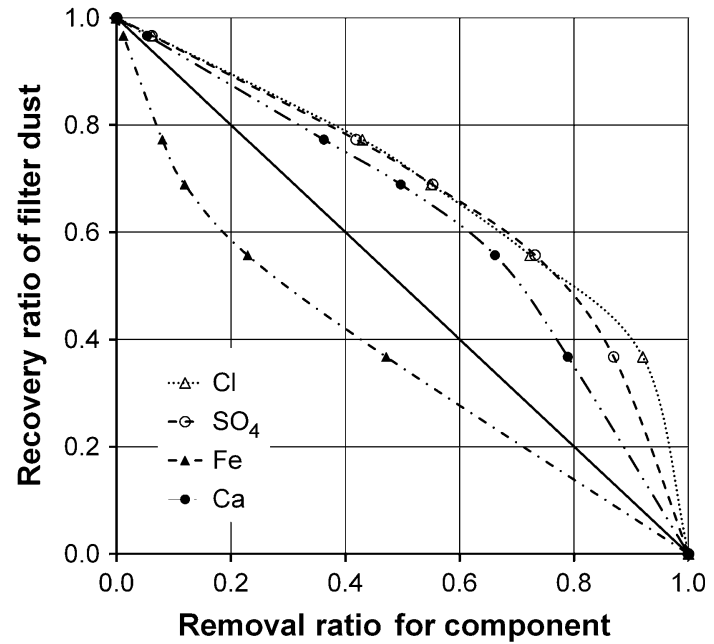

Fig. 6 Recovery ratio of combined residue for recycling compared with the removal ratio of various components

Consequently, without classification of the residue, about $58 \%$ of it would have to be disposed of. The aim of classification is the production of a maximized fraction of the residue for recycling to the sinter plant that contains no more than $42 \%$ of the chlorine. To keep the sulphur input constant, the limit for the amount of residue to be recycled would be even less $(31 \%)$.

The calculated functions of the recovery ratio of the combined residue in dependence of the removal ratio for certain components are shown in Fig. 6. For this calculation, the concentration of the components in the loss of the first classification run was assumed to be the same as in Particle Class 1 . As the particle size of the loss is certainly smaller than the particle size in Class 1 , this is a conservative estimate for those components which are accumulated in the fine particles. Furthermore, the mass fraction of 
Table 2 Recycling rates of various components

\begin{tabular}{|c|c|c|c|}
\hline & \multirow[t]{2}{*}{$\begin{array}{l}\text { Recycling of EP residue only } \\
(\%)\end{array}$} & \multicolumn{2}{|c|}{$\begin{array}{l}\text { Recycling of classified } \\
\text { combined residue }\end{array}$} \\
\hline & & $\begin{array}{l}\mathrm{Cl} \text { limited } \\
(\%)\end{array}$ & $\begin{array}{l}S \text { limited } \\
(\%)\end{array}$ \\
\hline $\begin{array}{l}\text { Total } \\
\text { mass }\end{array}$ & 70 & 66 & 59 \\
\hline $\mathrm{Cl}$ & 42 & 42 & 32 \\
\hline $\mathrm{S}$ & 31 & 41 & 31 \\
\hline $\mathrm{Fe}$ & 100 & 86 & 80 \\
\hline $\mathrm{Ca}$ & 29 & 47 & 38 \\
\hline
\end{tabular}

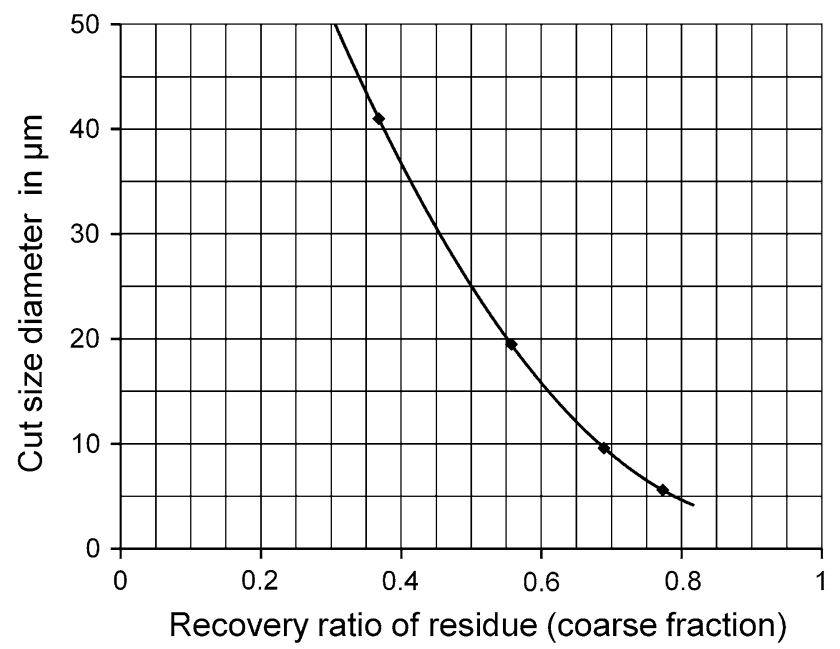

Fig. 7 Required cut size in the classification for a certain fraction of coarse material

the loss is relatively small. Therefore, no significant changes in the results are to be expected. The resulting recovery-removal functions for chlorine, sulphur and calcium are similar. For iron, the resulting recovery-removal function is below the neutral line which connects the points $(0 / 1)$ and $(1 / 0)$. This means that by separating a certain fraction of fine material from the combined residue, the fraction of iron in the fine material is smaller and therefore the recycled residue is iron-enriched.

Table 2 gives an overview of the recycling rates for various components for the different cases. The actual situation where the EP residue is recycled is the first case. Recycling of unclassified combined residue results, in the case of chlorine limitation, in recycling of $42 \%$ of the total mass of the residue as well as for each component, and in the case of sulphur limitation, in recycling of $31 \%$. For recycling of the classified combined residue, two cases were distinguished: one case chlorine recycling constant, the other sulphur-recycling constant. The recycling rate was kept constant in one case for chlorine and in the other case for sulphur. It is evident that the recycling rate for the total mass of the residue increases, whereas the recycling of chlorine and sulphur is similar. In comparison to the actual situation the recycling rate of iron is reduced in all cases considered. In contrast to this, the recycling rate for calcium is increased. The benefit of the classification would be a 1.6-1.9-fold increase in the recycled residue mass and an iron content of the recycled residue that is more than doubled.

Assuming similar behavior of the full-size classifier as the laboratory classifier, the required cut size of the classification can be obtained from Fig. 7 for a selected recovery rate of the residue. Such a full-size classifier with a cut size in the required range applying the same separation principle as the laboratory classifier, but with a capacity of $500 \mathrm{~kg} / \mathrm{h}$ of dust would be for example an ATP Turboplex classifier from Hosokawa (Hosokawa 2014).

\section{Conclusion}

Direct recycling to the sinter feed of the residue from the single-stage, dry de-dusting and desulphurization system of a sinter plant would result in remarkably reduced recycling rates because of limitations in the recycling rate for chlorine and sulphur. These limitations arise from the volatility of chlorine and sulphur containing components at the sintering temperature. The transfer of these components to the off-gas and their subsequent separation in the off-gas cleaning system would lead to a build-up in the system.

In the experiments, it was demonstrated that air classification is a suitable process for increasing the possible recirculation rate of residue in new single-stage, dry, offgas cleaning systems. In case of chlorine limitation, the recycling rate for the dust could be increased from 42 to $66 \%$ assuming an identical mass flow of chlorine back to the sinter plant as found in current EP dust recycling. This is close to the current recycling rate for the two-stage offgas cleaning system with recirculation of EP dust only where the recycling rate for the dust is $70 \%$.

Acknowledgments The financial support of K1-MET is acknowledged. K1-MET is member of COMET-Competence Centers for Excellent Technologies and is financially supported by the BMVIT (Federal Ministry for Transport, Innovation and Technology), BMWFJ (Federal Ministry of Economy, Family and Youth), the federal states of Upper Austria, Styria and Tyrol, SFG and Tiroler Zukunftsstiftung. COMET is managed by FFG (Austrian research promotion agency). The RFA analyses were done by Treibacher Industrie AG. The laboratory work of Mr. B. Benque is gratefully acknowledged.

\section{References}

Bastürk S, Delwig C, Ehler W, Hartig W, Hillmann C, Lüngen HB, Richter J, Schneider H, Zirngast J (2009) Technologien und 
Trends zur Abgasreinigung an Sinteranlagen. Stahl Eisen 129(5):51-59

Bonte L, Buttiens K, Fournelle R, Merchiers G, Pieters M (2003) New coal injection plant for dioxin reduction at the Sidmar sinter plants. Stahl Eisen 123(1):47-50

Buchwalder J, Hensel M, Richter J, Lychatz B (2008) Verminderung der Staubemissionen an der Sinteranlage von ArcelorMittal Eisenhüttenstadt. Stahl Eisen 128(9):111-117

Delwig C, Hartig W, Hoffmann M, Lüngen HB (2007) Developments in sinter technology. Stahl Eisen 127(6/7):S51-S66

EC (ed) (2012) Institute for Prospective Technological Studies, European IPPC Bureau best available techniques (BAT) Reference document for iron and steel production, industrial emissions directive 2010/75/EU, European Commission, Sevillia

Eisen HP, Groß J, Hüsig K-R, Kersting K, Stedem K-H (1996) Reduction of dust emissions in German sinter plants. In: Proceedings of 3rd Int. ironmaking congress, Gent, pp 165-169

Fleischanderl A, Neuhold R, Meierhofer G, Lanzerstorfer C (2006) MEROS $^{\circledR}$-improved dry-type gas-cleaning process for the treatment of sinter offgas. In: Proceedings of Iron\&Steelmaking Conference 2006, Linz, 11.4, pp 1-6

Gebert W (1996) Abgasreinigungssysteme für Sinteranlagen, Dissertation, Universität Kaiserslautern

Guerriero E, Guarnieri A, Mosca S, Rosetti G, Rotatori M (2009) $\mathrm{PCDD} / \mathrm{F}$ removal efficiency by electrostatic precipitator and wetfine scrubber in an iron ore sintering plant. J Hazard Mater 172:1498-1504. doi:10.1016/j.jhazmat.2009.08.019

Hosokawa (2014, July 16) Classifiers and air classifiers, Retrieved from the Hosokawa Alpine AG website https://www.hosokawaalpine.com/powder-particle-processing/machines/classifiers-andair-classifiers/

Kazyuta VI, Mantula VD, Shvets MN (2004) Ecology and resource conservation: bag filters for cleaning sintering gases. Steel Transl 34(11):68-73

Kim JR, Lee KJ, Hur NS (1997) Reduction of dust emission in sinter plant at Kwangyang works. Curr Adv Mater Process 10:799

Lanzerstorfer C, Fleischanderl A, Plattner T, Ehler W, Zwittag E (2008) Emissionsminderung bei Eisenerz-Sinteranlagen. In: VDI
Wissensforum GmbH (ed), Emissionsminderung 2008 StandKonzepte-Fortschritte, VDI-Bericht 2035, VDI Verlag, Düsseldorf, pp 161-170

Leroy J, Ravier E, Wajs A (2007) New abatement technique of the atmospheric emissions of large sinter plant. First results of industrial pilot in Arceloŕs Fos-sur-mer. In: Proceedings DustConf2007, April 23-24, Maastricht, S2/2, pp 1-2

Menad N, Tayibi H, Carcedo FG, Hernández A (2006) Minimization methods for emissions generated from sinter strands: a review. J Clean Product 14:740-747

Peng C, Zhang F-L, Guo Z-C (2009) Separation and recovery of potassium chloride from sintering dust of ironmaking works. ISIJ Int 49:735-742

Reidetschläger J, Stiasny H, Hötzinger S, Aichinger C, Fulgenico A (2012) Selective waste gas recirculation system for sintering plants. Stahl Eisen 132(1):25-30

Schuster E, Zirngast J, Zahn M (2005) Experiences with flue-gas cleaning by bag filter at the sinter strand of voestalpine stahl Donawitz. In: Proceedings of international conference on clean technologies in the steel industry, Balatonfüred, pp 292-300

Smit A, Leuwerink THP, van der Panne ALJ, Gebert W, Lanzerstorfer C, Riepl H, Hofstadler K (2000) Reduction of dioxin emissions from Hoogovens Sinter plant with the AIRFINE $^{\circledR}$ system. BHM 145:183-185

Weiss W (1998) Maßnahmen zur Verbesserung der Entstaubung einer Eisenerzsinteranlage mit nachfolgenden Untersuchungen zur Minderung der PADD/PCDF-Emissionen, Stahlwerke Bremen

Xu S, Liu J, Song M (2012) Water-washing of iron-ore sintering gas cleaning residue for beneficial reutilization as secondary construction material. Procedia Environ Sci 16:244-252. doi:10. 1016/j.proenv.2012.10.034

Yu Z, Li Q, Xu H, Lin C (2009) Design and Application of the DryFGD Process in Sanming Steel No. 2 Sintering Plant. In: Yan K (ed) Electrostatic Precipitation-11th Int. conf. on electrostatic Precipitation, Hangzhou 2008, Springer-Verlag, Berlin, pp 620-623 